\title{
CISTO CISTICERCóTICO INCLUIDO EM ADENONA DA SUPRA-RENAL
}

\author{
EHRENFRIED O. WitTIG * \\ Gilda KaSTING ** \\ Marcos Cravo*
}

A cisticercose, parasitose de alta incidência em nosso meio 1, 2, 3, 9, 10 aconmete todos os tecidos do organismo humano. Estatìsticamente sua distribuição no homem obedece a preferências de causas desconhecidas. A êste respeito Vosgien, citado por Canelas e Ricciardi-Cruz ${ }^{2}$, assinalou as seguintes localizações em 807 casos: olhos e anéxos $46 \%$; sistema nervoso $40 \%$; pele e tecido celular sub-cutâneo 6,32\%; músculos 3,47\%; outros orgãos 3,32\%.

$\mathrm{O}$ achado de cistos cisticercóticos associados a outra patologia também já foi referido algumas vêzes ${ }^{6,8}$. Entretanto na literatura que esteve a nosso alcance 4, 7,11,12 não encontramos caso algum em que cisto cisticercótico estivesse incluído dentro de adenoma da supra-renal, como ocorreu no que passamos a relatar. Embora se trate de achado de autópsia, o relato não deixa de ter interêsse.

\section{OBSERVACXAO NECROSCOPICA}

Cadáver do sexo masculino, de côr preta, com aproximadamente 60 anos de idade, indigente, encontrado morto em via pública em 17-5-1968, necrópsia n. ${ }^{\circ} 229 / 68$. Apresentava o cadáver infestação por cisticercos, massiça e difusa, na musculatura, no coração e no cérebro, todos em fase cística ou em início de degeneração. A supra-renal esquerda estava aumentada de volume mostrando uma formação nodular ocupando quase tôda a glândula, de forma ovalada, medindo aproximadamente $3 \mathrm{~cm} / 4 \mathrm{~cm} / 4 \mathrm{~cm}$, de côr cinza amarelada; aos cortes apresentava coloração cinzentoamarelada com pequenas áreas mais escuras e estrutura homogênea; em seu terço médio existia um cisticerco cístico de aproximadamente $1 \mathrm{~cm}$ de diâmetro. A microscopia revelou que o nódulo tumoral estava circundado por cápsula de tecido conjuntivo fibroso e formado por células corticais, sem disposição caracteristica, simulando por vêzes a disposição da camada glomerulosa, outras, a camada fasciculada. A maioria das células tinha citoplasma abundante, claro, e grande quantidade de lipóides. Os núcleos mostravam discreto pleomorfismo, alguns com atipias, outros com mitoses típicas ocasionais, observando-se, ainda, algumas células binucleadas. Centralizando a massa tumoral, existiam duas formaçóes císticas parecendo ser de natureza cisticercótica (diâmetro de $10 \mathrm{~mm}$ e $2 \mathrm{~mm}$ ) parcialmente calcificadas e isoladas do parênquima glandular, por cápsula fibrosa, discretamente infiltrada por leucócitos polimorfonucleares, alguns eosinófilos e mononucleares.

Do Serviço de Verificação de obitos do Instituto Médico Legal do Estado do Paraná (Diretor: Prof. Dr. Ernani S. Alves): * Médicos necropsistas; ** Patologista. 
238 ARQ. NEURO-PSIQUIAT. (SÃO PAULO) VOL. 27, N.? 3, SETEMBRO, 1969
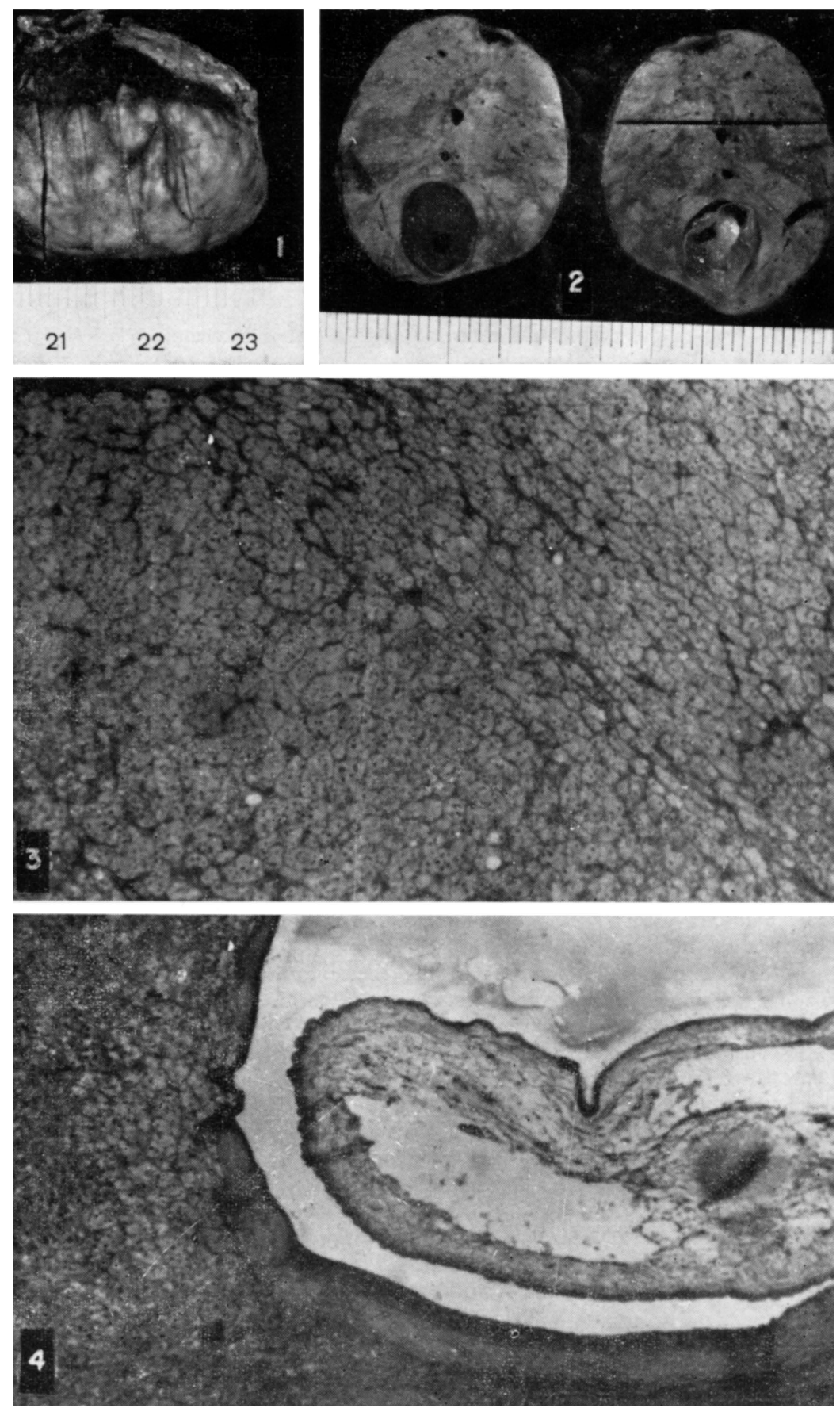
Zonas de calcificações foram encontradas na cápsula que isolava o parasita e no parênquima tumoral. Outras áreas da glândula examinada tinham aspecto normal mostrando grande quantidade de lipóides. Cisticerco localizado no músculo cardíaco apresentava escolex com acúleos. Diagnósticos: adenoma córtico-adrenal e cysticercus celllulosae.

\section{COMENTARIOS}

Em virtude da falta de informações quanto aos antecedentes "in vivo", torna-se impossivel determinar quais as possiveis manifestações clínicas decorrentes dos achados necroscópicos. Teria o cisticerco se alojado no tumor pré-formado ou teria êle sido a causa do desenvolvimento da neoplasia? Não há referência na literatura compulsada que permita admitir esta última eventualidade. Distúrbios endócrinos, secundários à localização de cisticerco, têm sido relatados em relação à patologia hipofisária ou da região hipotalâmica ${ }^{5}$.

\section{R E S M O}

Os autores fazem o registro de um caso anátomo-patológico de cisto cisticercótico incluído em adenoma de supra-renal. O caráver apresentava cisticercose no cérebro, na musculatura estriada e no coração. Na literatura compulsada não foi encontrada referência a caso semelhante. Em virtude da falta de informações quanto aos antecedentes não foi possível fazer correlação anátomo-clínica. Ê admitida a hipótese de que o parasita tenha se alojado no tumor pré-formado.

\section{S U M M A R Y}

Cysticercotic cyst enclosed in adrenal adenoma: a case report.

A cysticercotic cyst (C. cellulosae) enclosed in adrenal adenoma was found in post-mortem examination of a 60 years old man. There was massive cysticercoid infestation in brain, muscles and heart. It was not possible to collect clinical data. There is no similar case reported in the literature available to the authors.

\section{REFER N CIAS}

1. CANELAS, H. M. - Neurocisticercose: incidência, diagnóstico e formas clínicas. Arq. Neuro-Psiquiat. (São Paulo) 20:1, 1962.

2. CANELAS, H. M. \& CRUZ, O. R. - Neurocisticercose: formas clínicas pouco frequientes. Formas hemiplégicas. Arq. Neuro-Psiquiat. (São Paulo) 20:89, 1962.

Fig. 1 - Cisto cisticercotico incluido em adenoma supra-renal. Em 1, fotografia da glândula supra-renal com morfologia alterada pela tumoraçäo; em 2, corte da peça mostrando a tumoracão ocupando quase tôda a glândula $e$ apresentando, no seu interior, uma cavidade cística com características de cisticerco; em 3 , corte histológico da tumoração da glândula supra-renal, mostrando estar constituída por células cor. ticais sem arranjo característico, com citoplasma volumoso e carregado de lipidios (H.E. 125x); em 4, corte histológico ao nivel da cavidade cística, mostrando revestimento capsular fibroso, espesso, envolvendo cysticercus cellulosae (H.E. $80 x)$. 
3. CANELAS, H. M.; CRUZ, O. R. \& TENUTO, R. A. - Neurocisticercose: formas clínicas pouco freqüentes. Formas do ângulo ponto-cerebelar. Arq. NeuroPsiquiat. (São Paulo) 20:102, 1962.

4. FOROUGHI, E. - Calcified parenchimal cyst of the adrenal gland. J. Urol. 94: $504,1965$.

5. LIMA, G. J. C. - Cisticercose encefálica. Aspectos clínicos. Tese de Docência, São Paulo, 1966.

6. LOPES, C. F. \& ESCANDON, B. A. - Neurocisticercosis. Antioquia Medica 14:729, 1964.

7. MELONI, C. R. et al. - Cushing's syndrome due to bilateral adreno cortical hyperplasia caused by a benign adrenal medullary tumor. J. clin. Endocr. 26:1192, 1966.

8. ROCCA, E. D. \& MENDOZA, D. - Evoluación del tratamiento quirurgico en la neurocisticercosis. Rev. Med. Hosp. Obrero 9:390, 1956.

9. SPINA-FRANCA, A. - Incidência de neurocisticercose no Serviço de Neurologia do Hospital das Clínicas da Faculdade de Medicina da Universidade de São Paulo. Rev. paul. Med. (São Paulo) 43:160, 1953.

10. SPINA-FRANÇA, A. - Cisticercose do sistema nervoso central: considerações sôbre 50 casos. Rev. paul. Med. (São Paulo) 48:59, 1956.

11. VAN de MATTER, J. M. \& FONKALSRUD, E. W. - Adrenal cyst in infancy. Surgery 60:1267, 1966.

12. WEISS, J. M. \& SCHULTE, J. W. - Adrenal hemangiomas: a case report. J. Urol. 95:604, 1966.

Clínica Neurológica - Hospital de Clinicas - Curitiba, Paraná - Brasil. 